Kansas State University Libraries

New Prairie Press

\title{
APPLYING PRINCIPAL COMPONENT ANALYSIS TO SOIL- LANDSCAPE RESEARCH-QUANTIFYING THE SUBJECTIVE
}

R. David Hammer

John W. Philpot

Jon M. Maatta

Follow this and additional works at: https://newprairiepress.org/agstatconference

Part of the Agriculture Commons, and the Applied Statistics Commons

\section{(c) (1) $\Theta$}

This work is licensed under a Creative Commons Attribution-Noncommercial-No Derivative Works 4.0 License.

\section{Recommended Citation}

Hammer, R. David; Philpot, John W.; and Maatta, Jon M. (1990). "APPLYING PRINCIPAL COMPONENT ANALYSIS TO SOIL-LANDSCAPE RESEARCH-QUANTIFYING THE SUBJECTIVE," Conference on Applied Statistics in Agriculture. https://doi.org/10.4148/2475-7772.1436

This is brought to you for free and open access by the Conferences at New Prairie Press. It has been accepted for inclusion in Conference on Applied Statistics in Agriculture by an authorized administrator of New Prairie Press. For more information, please contact cads@k-state.edu. 


\title{
Applying Principal Component Analysis to Soil-Landscape Research-Quantifying the Subjective
}

\author{
R.David Hammer \\ Assistant Professor of Soil Science, University of Missouri, Columbia \\ John W. Philpot \\ Professor of Statistics, University of Tennessee, Knoxville \\ Jon M. Maatta \\ Assistant Professor of Statistics, University of Missouri, Columbia
}

\begin{abstract}
Principal component analysis is a multivariate statistical procedure that can be used to identify factors (correlated subsets of variables) in large data sets. This statistical method appears useful for scientists investigating soil processes, but it has received little attention. Reported applications of principal component analysis share a common fault--subjective, user-specified analytical options apparently are not recognized, for they are not discussed. Reported data sets are often small, have low observations-per-variable ratios, and lack tests of robustness. A large soil data set is used to demonstrate systematic procedures for an optimum rotated principal component solution. This solution retained 21 variables aligned among four "clean" and "logical" factors, and extracted $79 \%$ of the variance. Robustness was confirmed by comparison with common factor analysis solutions. When carefully applied, the presented guidelines should enhance scientists' abilities to identify and transfer knowledge about multivariate data sets, and should allow different scientists to independently arrive at similar factor solutions.
\end{abstract}

Rey words: factor analysis, communality, variance, robust.

\section{Introduction}

Eactor Analysis

Common factor analysis ( $F A$ ) is a statistical procedure designed to identify factors as correlated subsets of variables in large data sets. Principal component analysis (PCA) provides a set of components that, when rotated, can be used for the same purpose. It should be made clear that all references to PCA in this paper refer not to the initial principal components that

Contribution of Missouri Agric. Exp. Stn. Journal Series No. 11,238. 
can be extracted, but to the rotated components, or factors, that define the correlated subsets of variables; hence the use of the word "factors" throughout the paper. The essential difference between FA and PCA lies in the definition of the variance that is targeted for extraction, but both can be considered forms of factor analysis. In fact, major software designers (SAS, SPSS, STATGRAPHICS, and SYSTAT) have made principal components the default option in their factor analysis procedures.

Harman (1976) defined FA as an exploratory statistical device which will provide the best results when the "practitioner" understands ". . . at least in principle, what is going on in the analysis of a body of data. . ." In other words, some knowledge of the system being examined will be important in conducting and interpreting FA.

\section{Burden of Proef}

A survey of the literature in which PCA/FA are used to investigate soil-landscape and soil-site relationships revealed a distressing lack of consideration for important PCA/FA analytical procedures (Arp, 1984; Campbell et al., 1970; Fourt et al, 1971; La Bastide and Van Goor, 1970; Litaor et a1., 1989; Nortcliff, 1978; Ovalles and Collins, 1988; Page, 1976; Richardson and Bigler, 1984; Rowe and Sheard, 1981; Sarkar et al., 1966; Severson, 1981; Sondheim et al., 1981; Sondheim and Standish, 1983; Williams and Rayner, 1977). Since clear guidelines for determining the "optimum" final PCA/FA solution currently do not exist, we believe that the burden of proving that reported results are optimum lies with the investigators. A need exists for more complete and precise reporting of statistical methodology, particularly with "nontraditional" procedures. Lack of awareness of analytical methods used to produce reported results reduces confidence in the results and the methodology. More importantly, the ability to transfer knowledge from system to system is hindered. Among the deficiencies that can be found in the literature are:

1. Observations-per-variable ratio is not addressed (in some cases, investigators used fewer observations than variables);

2. Data sets often are extremely small, a problem accentuated when;

3. Robustness of the data is seldom addressed or tested;

4. Research objectives sometimes are not suited for $\mathrm{PCA} / \mathrm{EA}$;

5. Important methodologies are not discussed, including the procedures for determining the optimum number of extracted factors and criteria to determine which variables contribute to the variance extracted, and;

6. The criteria for an "optimum" solution are not discussed. 
Objectives

The objective of this manuscript is to present and discuss a methodology for a more systematic PCA/FA analysis. Specific emphasis will be given to determining which variables to retain in the data set and in extracting the optimum number of factors. A large data set of soil chemical and physical properties will be used as the template. Four complete rotated factor loading matrices will be presented so that the reader may begin to develop an appreciation of the the subtle changes which occur as the data are compressed into an optimum solution.

\section{Methodology}

\section{The Data Set}

Data were obtained as part of a research project designed to statistically evaluate a forest land classification for the Mid-Cumberland Plateau in Tennessee (Smalley, 1982; 1984). All soil profiles had A (surface) horizons, Bt (argillic horizons with high clay content), and transition horizons that were labelled $A B$ horizons. A total of 138 grid points was sampled. Soil physical properties measured in the field included horizon matrix color (from the Munsell charts), coded (Buntley and Westin, 1965) for statistical analyses, and horizon thicknesses.

\section{Basic Nomenclature and Principles}

Principal component analysis and common factor analysis ordinarily begin with the correlation matrix and are mathematically similar in many respects. The methods share the common goals of; 1) attempting to summarize intercorrelations among the variables, and 2) reducing a large number of variables to a smaller number of factors. The major difference in the two methods is the variance that is targeted for explanation. PCA attempts to account for all of the variance in the data set, as represented by the 1.0 values in the diagonal of the correlation matrix. Common factor analysis attempts to account for only that variance that is common to the variables sampled. For example, the shared variance for a given variable is often represented by the squared multiple correlation, $R^{2} j$, between the jth variable and the rest of the variables. Clearly $R^{2} j$ is less than or equal to 1.0. The focus on only that portion of the variance that is shared by the variables led to the phrase "common factor analysis". Detailed discussion is beyond the scope of this paper.

The remainder of this paper will center, for the sake of convenience, upon PCA and orthogonal rotations of the principal components into factors. The presented methodology applies equally well to FA. Factor analysis could be substituted for PCA throughout the manuscript without changing the relevance of interpretations.

The general PCA model, after orthogonal rotation, can be represented by: 


$$
z_{j}=a_{j 1} E_{1}+a_{j 2} E_{2}+\cdot \cdot \cdot a_{j m} E_{m}
$$

where any variable $\left(z_{j}\right)$ is represented by the sum of its loadings ( $\left.a_{j i} \cdot . \cdot a_{j m}\right)$ onto the factors $\left(E_{1} \cdot \cdot E_{m}\right)$. The $a_{j k}$ values form an $n-b y-m$ factor matrix, each row of which shows how that variable loads on the $m$ factors. Each column of the matrix shows the relative strength of the variables in that factor. The factor is characterized by those variables which load primarily upon it. "Primary loaded" variables should account for most of the variance extracted by the factor. The total variance $\left(s^{2} k\right)$ the factor extracts from the data is the sum of the squared factor loadings in the kth column, or:

$$
s^{2} k=a^{2} 1 k+\cdot \cdot a^{2} n k ;
$$

where "l" through "n" represent individual variables. A single factor is a vector in space which contains positive and negative loadings. These "directions," as well as the variables themselves, will determine the user's interpretation of the factor.

The estimation of the correlation matrix during PCA is characterized by the use of communalities to estimate the "I's" on the diagonal. The communality $\left(h^{2} j\right)$ of a variable, $j$, is the sum of the squared factor loadings of the variable (row $j$ of the matrix):

$$
h^{2} j=a^{2} j 1+a^{2} j 2+\cdot \cdot \cdot a^{2} j m,
$$

and represents the amount of variance of that variable that is captured by the factors. Low communalities indicate that the variable is somewhat unique, and doesn't cluster well with the other variables in the data set. Such variables are inappropriate for factor analysis.

\section{Statistical Methods}

The procedures and definitions detailed below have been used for a number of years in a graduate level Factor Analysis course taught at the University of Tennessee by Dr. Philpot. The procedures have been tested on data from the behavioral and biological sciences. The PCA analysis described below was performed on a MacIntosh SE with an accelerator board and SYSTAT version 3.2 software (Wilkinson, 1986). The FA results with which the PCA analysis is compared were obtained using SAS (SAS Institute Inc, 1982) mainframe software, using the same iterative techniques.

Assumptions made prior to these analyses and adhered to during the search for the "best" PCA/EA solution were: 1) the optimum number of factors and variables is not known, and will 
be determined during the analysis; 2) judgement and statistical procedures will be used together to determine the final solution; and 3 ) the final solution, if valid, will be "logical" (it will make sense) and "clean" (will consist of variables strongly aligned upon factors and will have few secondary loadings).

Interpreting the Factor Matrix

Each stage leading to a final PCA solution requires determining the optimum number of factors to extract and deciding which variables to retain in the data set. The rotated PCA solution should consist of factors which each contain several correlated variables which are "primarily" loaded upon that factor. Factors should have few secondary loadings. Each variable will load onto all factors in the solution, but should load primarily onto one factor. The objective here is to achieve a simple, easily interpreted factor matrix via orthogonal rotation.

The factor matrix can be developed almost like a print is developed in the darkroom. The procedure for finding the structure inherent in the factor matrix is:

1. Calculate the mean and standard deviation of the communalities of all variables involved. For any variables having communalities more than two standard deviations below the mean, the corresponding row of the factor matrix should be deleted.

2. Examine the remaining rows of the factor matrix. Highlight the (absolute) maximum loading in each row. These are primary loadings.

3. Find the (absolute) minimum of the primary loadings. This value determines the lower boundary of the salient loadings.

4. Highlight all other (absolute) loadings in the factor matrix that equal or exceed the boundary value found in step 3. These are secondary loadings. The salient loadings consist of the primary loadings for each variable plus any secondary loadings.

5. Re-analyze using only those variables with robust communalities and only those factors that are well defined by three or more salient loadings.

Table 1 is an example of a rotated loading score matrix. The primary loading of a variable is the highest absolute value of all its loading scores. In this case, the primary loading of organic matter is 0.712 on factor 2. Calcium (Ca) loads primarily onto factor 1 , and magnesium (Mg) loads primarily onto factor 2. The minimum primary loading is 0.448 , which becomes the boundary value. A secondary loading occurs when the absolute value of a non-primary loading of a variable equals or exceeds the boundary value. In table 1 , calcium has a secondary loading on factor 2 because the loading score of 0.452 exceeds 
0.448. Large numbers of secondary loadings in an analysis create ambiguity and decrease the clarity of interpretations.

Factor Extraction

The initial number of factors to extract is often based on one of two criteria--a scree plot or the number of eigenvalues greater than 1. Alternatively, an extraction with $\mathrm{n} / 3$ factors, where $n$ is the number of variables, should provide a good starting point. After the initial extraction, the number of factors will be depend on the pattern of salient loadings. A factor should contain at least three variables with salient loadings to be considered for retention.

\section{Variable Retention}

Two criteria were used to determine which variables to retain--variable "behavior" and the distance of the communality of each variable from the mean communality for that extraction. Variable "behavior" refers to the persistence of alignment of individual variables with correlated variables upon a factor. Variables should not "jump around" from one stage of the analysis to the next.

Robustness and Observations-per-Variable Ratio observation-to-variable ratio is an important topic not well addressed in the literature. Tabachnick and Fidell (1983) recommended a minimum of 100 samples and suggested that 1000 observations would be optimum. Kendall (1975) suggested that the number of observations should be 10 times the number of variables. The rule of thumb philpot developed through teaching and research experience is that $n *(n-1) / 2$ is the preferred number of observations for $n>7$ (where $n$ is the number of variables), and $3 \mathrm{n}$ is the minimum acceptable ratio. This study utilized 138 observations on three soil horizons. A total of 38 soil variables resulted (Table 2 ).

Tabachnick and Fidel (1983) suggested that robustness be verified by splitting the data set and performing, then comparing, separate analyses. Ideally, similar results should be achieved. The time and expense required to build a robust soils data set from field and laboratory analyses generally precludes this technique. Robustness of the data analyzed in this project was tested by subjecting the data to FA solutions using Minimum Residual (MINRES), Maximum Iikelihood, and Image analyses, and comparing them with PCA. This approach is patterned after the recommendations of Harris (1967).

\section{Results and Discussion}

Changes in variable alignment, factor loadings and variance extracted were observed as the data were systematically compressed into the optimum solution. Careful observation of the rotated factor loading matrices provides insight into relationships among the variables. More importantly, the changes observed in successive stages underscore the importance 
of bringing careful, objective logic to PCA/EA analyses. Four of the rotated factor loading matrices are compared and discussed to illustrate this point.

The analyses required 13 stages to reach a final solution. Table 3 summarizes the progression of steps to the final (optimum) PCA solution, which contained 17 fewer variables and four fewer factors than the second stage. The fluctuation in the minimum communality is noteworthy, and ranged from 0.163 (third stage) to 0.723 (ninth stage). As variables with low communalities were progressively dropped, the minimum communality rose steadily. The optimum solution, which had a minimum communality of 0.701 and no secondary loadings, indicates that all of the retained variables extracted high variance and were strongly aligned with a particular factor.

Table 4 is the rotated factor loading matrix of the 38 original variables on six factors, and is from the third stage (Table 3). Calcium in the A horizon has three secondary loadings (on factors 1,4 , and 5) and is aligned with $\mathrm{K}$ and $\mathrm{Mg}$ on factor 6. The three secondary loadings indicate that excessive "noise" exists. The number of secondary loadings in the matrix (20) indicates great ambiguity in this solution.

The communalities of $\mathrm{pH}\left(\mathrm{H}_{2} \mathrm{O}\right)$ in the $\mathrm{Bt}$ and extractable acidity in the $\mathrm{AB}(0.163$ and 0.245$)$, respectively, were more than two standard deviations from the mean, so these variables were dropped prior to the fourth stage. The fourth stage revealed that two more variables ( $\mathrm{pH}$ ( $\mathrm{KCl}$ ) in the Bt horizon and thickness of the $A B$ horizon) had communalities sufficiently low to warrant their removal. The fifth stage (Table 5) contained 34 variables and 6 factors.

Comparison of tables 4 and 5 reveals interesting changes in the composition of the rotated factor loading matrix after dropping four variables. Factor 5 remained virtually unchanged, accounting for $7.8 \%$ of the variance and loaded primarily by the same variables. Factors 1 and 3 seemed to change places between the third and fifth stages. The variables aligned upon factor 1 in Table 4 aligned upon factor 3 in Table 5, and the amount of variance extracted increased to $18.6 \%$ from $17.7 \%$. Four fewer variables are contributing to the variance, but the stronger alignment of the remaining variables increased the variance extracted by factor 3. The variable "A horizon clay" loaded primarily onto factor 6 in the third stage, but by the fifth stage it had aligned onto factor 1 with several other textural variables. Variables associated with factor 2 did not change, but the signs of the loading scores were reversed. The total amount of variance extracted by the factors increased from $70.2 \%$ to $75.8 \%$ during the two stages. The changes resulting from removal of four variables illustrate the importance of some degree of uniformity in deciding how to determine and report the optimum PCA/EA solutions of large multivariate data sets.

A subjective decision was made at this juncture in the analysis. Alignment of the textural variables was not so "clean" as had been expected. A colleague (G.J. Buntley, 
personal communication) suggested that fine silts would behave like clays and that fine sands and very fine sands would behave like coarse silts. The 10 textural variables were combined into four classes. Within horizons, fine sands, very fine sands, and coarse silts were combined into a single variable called "silt" and clay and fine silt were combined into a variable called "clay."

Results of combining the textural variables were very satisfactory (Table 6 ). The textural variables together aligned primarily onto a single factor which accounted for $14.4 \%$ of the extracted variance. The alignment of textural variables left the A horizon cations (except $\mathrm{Na}$ ) aligned upon a single factor with organic matter. The new factor 1, loaded primarily by cations from the $A B$ and $B t$ horizons, extracted $21.6 \%$ of the variance. This was the first stage in which the ultimate variable alignment began to become apparent. Three variables ( $N a$ in the $A B$ and $B t$ horizons, and $A$ horizon color) possessed communalities more than two standard deviations below the mean, and were dropped from the subsequent stage.

Factor 4 of the seventh stage had primary loadings for only the two A horizon pH variables, and no secondary loadings. The correlation matrix revealed a correlation coefficient between these two variables of 0.911 . The high correlation indicated that the two variables could be considered as one in this horizon. Since there were fewer than three salient loadings, the decision was made to reduce the number of factors by one.

The eighth stage revealed that organic matter and $\mathrm{Na}$ in the A horizon had low communalities, so they were dropped. The ninth stage contained one factor (number 5) loaded primarily by only two variables from the A horizon--extractable acidity and thickness. The factor accounted for only $7 \%$ of the variance, and the correlation coefficient between the two variables was only -0.464, so a subjective decision was made to compress the data further by removing one more factor. The two variables were dropped subsequentiy because of low communalities. They had loaded onto a shared factor not because they were highly correlated, but because they were not strongly correlated with variables aligning upon the more robust factors. The preceding discussion illustrates the importance of consulting the correlation matrix when considering relationships among variables in the rotated factor loading scores matrix.

The twelfth stage resulted in no secondary loadings and no communalities more than two standard deviations from the mean. Four robust factors each contained several correlated primary loaded variables (Table 7). This was deemed the "optimum" solution after subsequent compression to 3 factors resulted in an increase in secondary loadings (from 0 to 4 ) and a reduction in variance extracted (from 79.3\% to $70.9 \%$ (Table 3)). The final solution was "clean" and "logical." The four factors could be named according to the variables loaded upon them, as indicated in table 8.

The variables dropped from the data set during compression to the final solution accounted for a total of only $22.4 \%$ of the 
variance extracted from the first stage of 12 factors and 38 variables.

One could logically argue that the eleventh stage would have been an acceptable final solution. It contained no secondary loadings and differed from the 12th stage primarily in that A horizon thickness was dropped. Comparison of this rotated PCA solution with several FA solutions and a rotated PCA solution using SAS (SAS, 1982) software indicates that A horizon thickness was retained by Maximum Likelihood analysis and Minimum Residuals, but was dropped in Image analysis and in the other PCA analysis (Table 9). Results of the four procedures were very similar. The data used in this analysis appear to be robust.

One might question how the data would have behaved had the textural variables been combined prior to the first stage rather than part way through the analyses. To test this concern, the analysis was repeated from the beginning, using the same procedures and guidelines upon the data, but with the textural variables combined. The same results were obtained. The same variables were retained, and the same alignment was achieved

\section{Conclusions}

The various FA procedures and rotated PCA produced "clean," "logical" final solutions. The methods used to obtain the optimum solution produced similar results with all procedures, indicating that different investigators could probably arrive independently at the same conclusions following the suggested guidelines.

Knowledge of the subject matter and reference to the correlation matrix were essential in arriving at the final solution. Deming's (1960) observation ". . .mathematics, judgement, and substantive knowledge work together to the best advantage." is particularly apropos for multivariate analyses. One should not expect the statistical procedures to sort all the noise from the data. In the hands of the careful, competent investigator, the subjective nature of these multivariate statistical procedures is not a detriment. On the contrary, the astute investigator obtains valuable insight into the structure and relationships of the variables as the optimum solution is developed.

The analyses reduced a large, complex data set to four logical factors, and indicated that approximately one fourth of the variables made minimal contributions to the structure of the data set. Subsequent analysis of soil-landscapes in this region could focus upon the correlated variables. This would allow investigators to build larger data sets without additional expenditures for laboratory analyses. 


\section{Ackrowledgements}

Eield and laboratory research were conducted while the senior author was a research associate at the University of Tennessee, Knoxville. The authors thank R.J. Miles for assistance with field sampling and G.W. Smalley, W.I. Parks, and G.J. Buntley for encouragement and support during field and laboratory efforts. The research was a cooperative agreement between the Institute of Agriculture and the U.S.D.A Eorest Service. Partial funding was provided through grant number FS19-81-34 from the U.S. Forest Service, Southern Eorest Exp. Stn., New Orleans, LA.

\section{References}

Arp, P.A. 1984. Eorest floor variability and factor analysis: A case study. Can. J. Soil Sci. 54: 457-461.

Buntley, G.J. and E.C. Westin. 1965. A comparative study of developmental color in a Chestnut-Chernozem-Brunizem soil climosequence. Soil Sci. Soc. Am. Proc. 29: 579-582.

Campbel1, N.A., M.J. Mulcahy, and W.M. McArthur. 1970. Numerical classification of soil profiles on the basis of field morphological properties. Aust. J. Soil Res. 8: 4358.

Deming, W.E. 1960. Sample design in business research. Wiley Classics Library Ed. pub. 1990. Wiley Interscience, NY.

Fourt, D.F., D.G. M. Donald, J.N.R. Jeffers, and W.O. Binns. 1971. Corsican pine (Pinus nigra var. maritima (Ait.) Melville) in Southern Britain. Forestry 44: 189-207.

Gorsuch, R.I. 1974 Factor Analysis W.B. Saunders Co., Philadelphia.

Harman, H.H. 1976. Modern factor analysis. 3rd Ed., Univ. of Chicago Press, Chicago.

Harris, C.W. 1967. On factors and factor scores. Psychometricka 32: 363-379.

Johnson, R.A, and D.W. Wichern. 1988 Applied Multivariate Statistical Analysis, 2nd Ed. Prentice Hall, Englewood Cliffs, N.J.

Kendall, M. 1975. Multivariate analysis. Hafner Press, NY. 
Kim, J O., and C.W. Mueller. 1978 Factor Analysis: Statistical Methods and Practical Issues. Sage Publications, Beverly Hills

La Bastide, J.G.A. and C.P. Van Goor. 1970. Growth-site relationships in plantations of Pinus elliottii and Araucaria angustifolia in Brazil. Plant and soil 32: $349-366$.

Litaor, M.I., Y. Dan, and H. Koyumdjisky. 1989. Factor analysis of a lithosequence in the northestern Samaria Steppe (Israel). Geoderma 44: 1-15.

Nortcliff, S. 1978. Soil variability and reconnaissance soil mapping: A statistical study in Norfolk. J. Soil Sci. 29: 403-418.

Ovalles, F.A. and M.E. Collins. 1988. Variability of northwest Florida soils by principal component analysis. Sail sci. Soc. Am. J. 52: 1430-1435.

Page, G. 1976. Quantitative evaluation of site potential for spruce and fir in Newfoundland. Forest Sci. 22: 131-143.

Richardson, J.I. and R.J. Bigler. 1984. Principal component analyses of priaire pothole soils in North Dakota. Soil Sci. Soc. Am. J. 48: 1350-1355.

Rowe, J.S. and J.W. Sheard. 1981. Ecological land classification: A survey approach. Environ. Manag. 5: $451-464$.

Sarkar, P.K., O.W. Bidwell, and L.E. Marcus. 1966. Selection of characteristics for numerical classification of soils. Soil Sci. Soc. Am. Proc. 30. 269-272.

SAS Institute Inc. 1988. SAS/STAT Users' Guide: Release 6.03 ed. SAS Institute Inc., Cary, NC.

Severson, R.C. 1981. Evaluating chemical character of soil material for suitability in rehabilitating mined land in the San Juan Basin, New Mexico. Soil Sci. Soc. Am. J. 45: 396-404.

Smalley, G.W. 1982. Classification and evaluation of forest sites on the mid-Cumberland Plateau. U.S.D.A. Eorest Serv. Gen. Tech. Rep. So-38.

Smalley, G.W. 1984. Landforms: A practical basis for classifying forest sites in the interior uplands. pp. 92112. In Proceedings, 12th Annual Hardwood Sympopsium, Hardwood Research Council, Chashiers, North Carolina. 
Sondheim, M.W., G.A. Singleton and L.M. Lavkulich. 1981. Numerical analysis of a chronosequence, including the development of a chronofunction. Soil Sci. Am. J. 45: 558-563.

Sondheim, M.W. and J.T. Standish. 1983. Numerical analysis of a chronosequence including an essessment of variability. Can. J. Soil Sci. 63: 501-517.

SPSS Inc. 1990 SPSS Reference Guide. SPSS Inc., Chicago, III.

STST InC. 1988 STATGRAPHICS User's Guide: Statistical Graphics System STSC Inc., Rockville, Md.

Tabachnick, B.G. and I.S. Fidell. 1983. Using multivariate statistics. Harper and Row, New York.

Wilkinson, I, 1986. SYSTAT: The system for statistics. SYSTAT, Inc., Evanston, Il.

Williams, C. and J.H. Rayner. 1977. Variability in three areas of the Denchworth soil map unit. III. Soil grouping based on chemical composition. J. Soil Sci. 28: 180-195. 
Table 1. Examples of primary and secondary loacings on a rotated factor loading score matriz.

\begin{tabular}{lcc}
\hline VARIABLE & FACTOR 1 & FACTOR 2 \\
Organic matter & -0.038 & $0.712^{\circ}$ \\
Ca & $0.561^{\circ}$ & $-0.452^{\circ}$ \\
& 0.115 & $-0.448^{\circ}$ \\
& & \\
\hline Primsey londing & & \\
\hline Secondiary loading & &
\end{tabular}

Table 2. Variables usad in the Principal Component Anatysis. The " $z$ " indicates that the variable was included in the data set

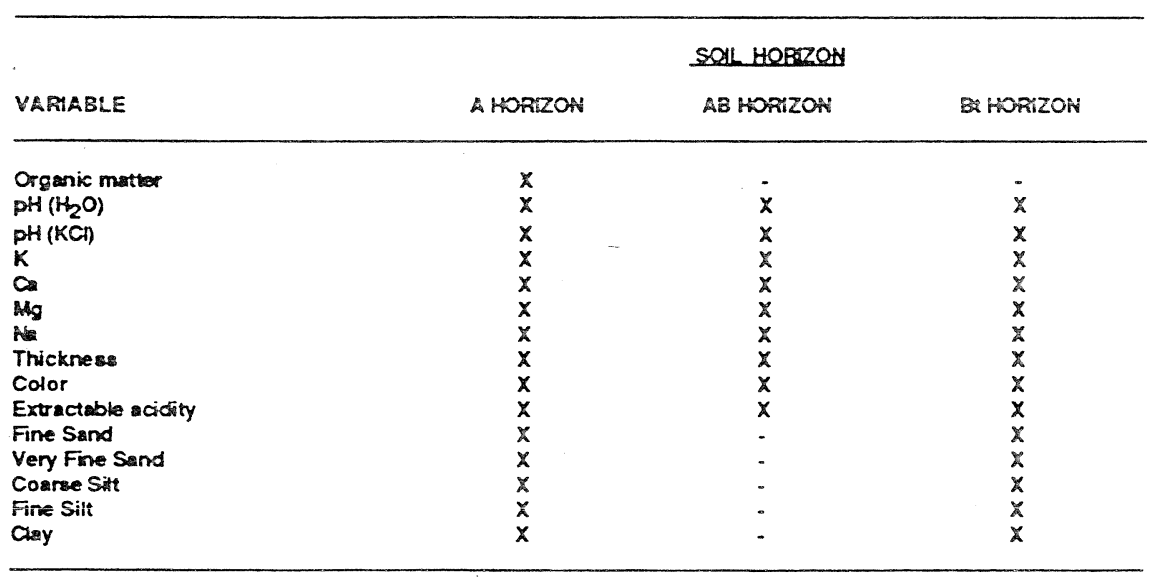

Table 3. Characteristica of stages leading to final factor solution.

\begin{tabular}{|c|c|c|c|c|c|c|c|c|c|}
\hline Stage & Factors & Variables & Mean & $\frac{\text { munalitis }}{\text { Whax }}$ & Min & $\begin{array}{l}\text { Secondsry } \\
\text { Loadings }\end{array}$ & $\begin{array}{c}\text { Eigen. } \\
>1\end{array}$ & $\begin{array}{l}\text { \% Var. } \\
\text { Extracted }\end{array}$ & $\begin{array}{l}\text { Variables } \\
\text { Dropped }\end{array}$ \\
\hline 1 & 12 & 38 & - & - & - & - & 8 & 79.88 & $\longrightarrow$ \\
\hline 2 & 8 & 38 & 0.764 & 0.944 & 0.420 & 7 & 8 & 76.54 & $\longrightarrow$ \\
\hline 3 (Tabse 4) & 6 & 38 & 0.702 & 0.841 & 0.163 & 20 & 8 & 70.21 & $\begin{array}{l}\mathrm{pH}(\mathrm{H} 2 \mathrm{O}) \mathrm{Bt} \\
\text { Extractable scid. (AB) }\end{array}$ \\
\hline 4 & 6 & 36 & 0.734 & 0.940 & 0.424 & 0 & 7 & 73.37 & $\begin{array}{l}\text { pH(KCI)Bt } \\
\text { Thickness (AB) }\end{array}$ \\
\hline 5 (Tab 5$)$ & 6 & 34 & 0.758 & 0.246 & 0.480 & 4 & 6 & 75.78 & $\begin{array}{l}\text { Combine textural } \\
\text { variabies }\end{array}$ \\
\hline 6 (Table 6) & 6 & 28 & 0.781 & 0.820 & 0.557 & 0 & 6 & 78.13 & $\begin{array}{l}\mathrm{Na}(\mathrm{AB}), \mathrm{NQ} / \mathrm{Bt}) \\
\text { Cotor }(A)\end{array}$ \\
\hline 7 & 5 & 25 & 0.821 & 0.818 & 0.705 & 0 & 6 & 82.12 & $t$ \\
\hline 8 & 5 & 25 & 0.778 & 0.813 & 0.583 & 3 & 6 & 77.88 & Organic matter, $\mathrm{Na}$ (A) \\
\hline 9 & 5 & 23 & 0.805 & 0.815 & 0.723 & 1 & 4 & 80.39 & $t+$ \\
\hline 10 & 4 & 23 & 0.762 & 0.804 & 0.403 & 3 & 4 & 76.19 & Extractable acid. (A) \\
\hline 11 & 4 & 22 & 0.781 & 0.806 & 0.575 & 0 & 4 & 77.53 & Thickness (A) \\
\hline $12 \$(T) 7)$ & 4 & 21 & 0.783 & 0.909 & 0.701 & 0 & 4 & 78.26 & $\longrightarrow$ \\
\hline 13 & 3 & 21 & 0.702 & 0.844 & 0.377 & 4 & 4 & 70.86 & \\
\hline
\end{tabular}

$\dagger \quad$ Dropped one factor. Factor 4 was loaded only by the two $\mathrm{PH}$ variables in the A horizon

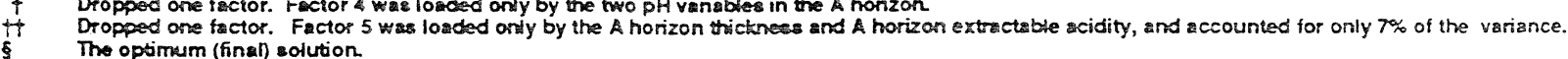




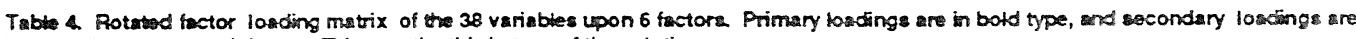
ind callod with an (2) This was the third stage of the solution.

\begin{tabular}{|c|c|c|c|c|c|c|}
\hline \multirow[b]{2}{*}{ VARABLE } & \multirow[b]{2}{*}{1} & \multirow[b]{2}{*}{2} & \multicolumn{2}{|c|}{ FACTOR } & \multirow[b]{2}{*}{5} & \multirow[b]{2}{*}{6} \\
\hline & & & 3 & 4 & & \\
\hline 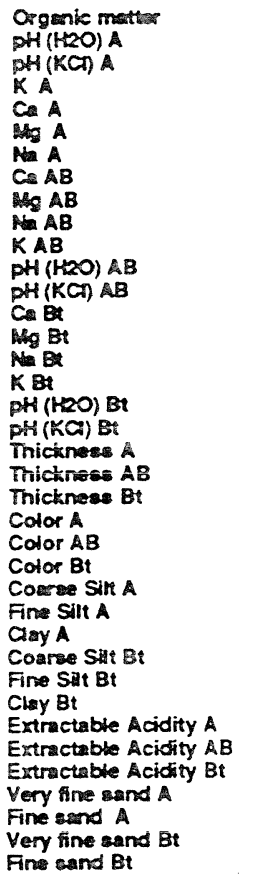 & $\begin{array}{l}0.017 \\
-0.194 \\
-0.289 \\
0.333 \\
0.393^{\circ} \\
0.245 \\
0.127 \\
0.918 \\
0.811 \\
-0.112 \\
0.860 \\
-0.748 \\
0.580 \\
0.885 \\
0.812 \\
0.204 \\
0.683 \\
-0.032 \\
-0.207 \\
0.428 \\
-0.074 \\
-0.144 \\
0.033 \\
0.183 \\
0.124 \\
0.063 \\
0.129 \\
0.275 \\
0.215 \\
0.248 \\
0.261 \\
-0.338 \\
0.418 \\
0.324 \\
-0.079 \\
0.296 \\
-0.151 \\
-0.204\end{array}$ & $\begin{array}{r}-0.016 \\
0.009 \\
0.026 \\
0.045 \\
0.008 \\
0.072 \\
0.593 \\
0.164 \\
-0.142 \\
-0.006 \\
0.023 \\
0.354 \\
-0.253 \\
0.163 \\
-0.091 \\
-0.203 \\
0.081 \\
-0.060 \\
0.194 \\
0.053 \\
-0.050 \\
0.730 \\
-0.066 \\
-0.575 \\
-0.705 \\
-0.089 \\
-0.120 \\
0.280 \\
-0.117 \\
0.037 \\
-0.510 \\
0.175 \\
0.026 \\
0.726 \\
0.863 \\
-0.086 \\
-0.789 \\
2.010\end{array}$ & $\begin{array}{c}0.160 \\
0.132 \\
0.195 \\
0.139 \\
0.105 \\
0.248 \\
-0.050 \\
0.020 \\
0.234 \\
-0.349 \\
0.116 \\
0.159 \\
0.475 \\
0.073 \\
0.152 \\
-0.060 \\
0.305 \\
0.027 \\
0.568 \\
0.038 \\
0.425 \\
0.118 \\
0.048 \\
0.060 \\
0.171 \\
0.402 \\
0.807 \\
0.321 \\
0.728 \\
0.730 \\
0.246 \\
-0.114 \\
0.113 \\
-0.314 \\
-0.084 \\
-0.712 \\
-0.211 \\
-0.753\end{array}$ & $\begin{array}{c}-0.040 \\
-0.808 \\
-0.787 \\
0.354^{\circ} \\
0.467^{\circ} \\
0.462^{\circ} \\
-0.273 \\
0.195 \\
0.123 \\
0.674 \\
0.072 \\
-0.075 \\
-0.143 \\
0.198 \\
0.214 \\
0.019 \\
0.210 \\
0.040 \\
-0.125 \\
0.362^{\circ} \\
0.054 \\
0.149 \\
0.358^{\circ} \\
-0.433^{\circ} \\
-0.259 \\
0.116 \\
-0.240 \\
0.348^{\circ} \\
0.119 \\
0.064 \\
-0.075 \\
-0.097 \\
-0.192 \\
0.169 \\
0.182 \\
-0.192 \\
0.190 \\
-0.172 \\
\end{array}$ & $\begin{array}{r}0.011 \\
0.003 \\
-0.158 \\
0.408 \\
0.348^{4} \\
0.213 \\
0.277 \\
0.002 \\
0.187 \\
0.092 \\
0.091 \\
-0.240 \\
-0.110 \\
0.073 \\
0.095 \\
0.633 \\
0.278 \\
0.347 \\
0.061 \\
0.673 \\
0.452 \\
-0.011 \\
0.651 \\
0.275 \\
0.390 \\
0.094 \\
0.059 \\
-0.053 \\
-0.083 \\
0.205 \\
0.072 \\
0.655 \\
-0.131 \\
-0.124 \\
0.104 \\
-0.183 \\
-0.025 \\
-0.171 \\
\end{array}$ & $\begin{array}{r}0.843 \\
-0.180 \\
-0.178 \\
0.683 \\
0.610 \\
0.709 \\
0.348 \\
0.020 \\
0.205 \\
-0.052 \\
0.056 \\
0.073 \\
0.306 \\
0.152 \\
0.290 \\
0.207 \\
0.314 \\
0.188 \\
0.008 \\
0.219 \\
-0.062 \\
0.315 \\
-0.058 \\
-0.253 \\
0.156 \\
0.680 \\
0.026 \\
0.504 \\
0.263 \\
0.292 \\
0.335 \\
0.220 \\
0.055 \\
-0.059 \\
0.055 \\
-0.517 \\
0.126 \\
0.373 \\
\end{array}$ \\
\hline Variance Extracted $(\%)$ & 17.7 & 11.6 & 12.1 & 9.4 & 7.8 & 11.5 \\
\hline
\end{tabular}

Table 5. Rotated factor loading mstrix after 5 atager. Primery loadinge are in bold type. Secondary loadings are indicated with an asterisk (\%).

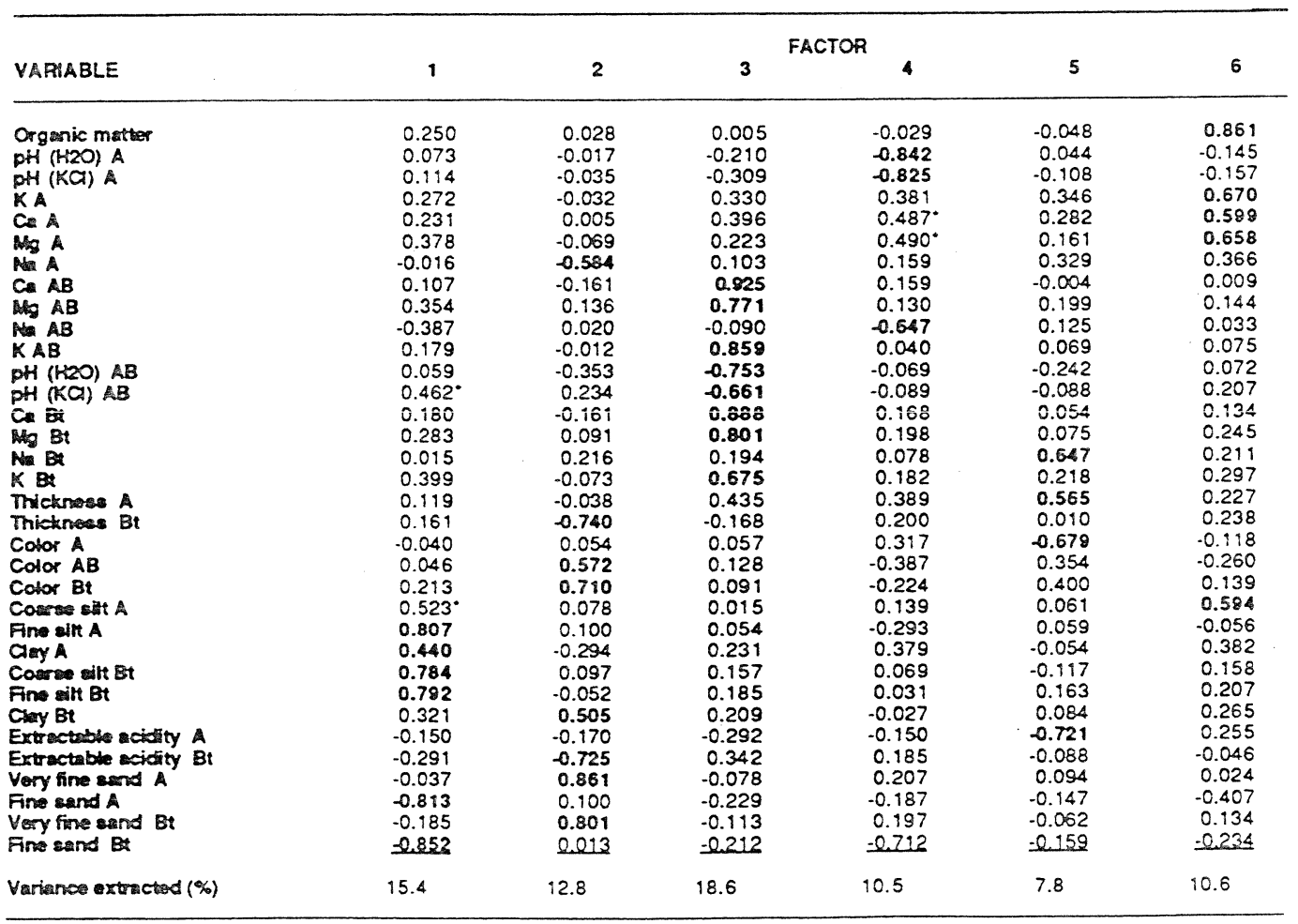




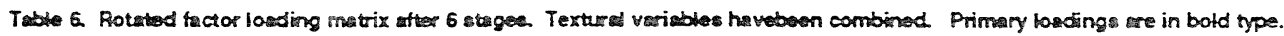

\begin{tabular}{|c|c|c|c|c|c|c|}
\hline \multirow[b]{2}{*}{ VAPEABLE } & \multicolumn{6}{|c|}{ FACTOR } \\
\hline & 1 & 2 & 3 & 4 & 5 & 8 \\
\hline 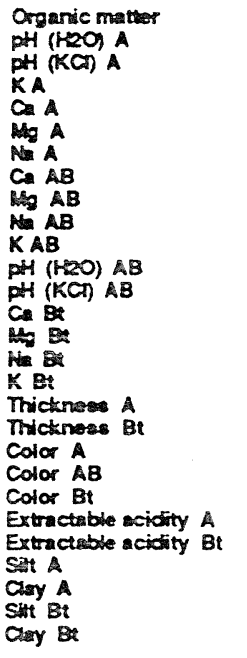 & $\begin{array}{r}-0.005 \\
-0.187 \\
-0.287 \\
0.313 \\
0.378 \\
0.204 \\
0.090 \\
0.821 \\
0.753 \\
-0.084 \\
0.846 \\
-0.755 \\
-0.681 \\
0.882 \\
0.791 \\
0.183 \\
0.664 \\
0.425 \\
-0.180 \\
0.056 \\
0.114 \\
0.073 \\
-0.278 \\
0.339 \\
-0.267 \\
0.179 \\
-0.170 \\
0.207\end{array}$ & $\begin{array}{r}0.029 \\
0.113 \\
0.110 \\
-0.098 \\
-0.065 \\
-0.110 \\
0.607 \\
-0.161 \\
0.173 \\
0.003 \\
0.027 \\
-0.330 \\
0.300 \\
-0.156 \\
0.098 \\
0.176 \\
-0.034 \\
-0.075 \\
0.759 \\
-0.018 \\
0.673 \\
0.743 \\
-0.218 \\
-0.789 \\
0.312 \\
0.000 \\
0.183 \\
0.283\end{array}$ & $\begin{array}{r}0.232 \\
0.039 \\
0.071 \\
0.315 \\
0.269 \\
0.418 \\
0.170 \\
0.154 \\
0.380 \\
-0.356 \\
0.211 \\
0.133 \\
0.418 \\
0.241 \\
0.288 \\
0.021 \\
0.429 \\
0.172 \\
0.352 \\
-0.039 \\
-0.016 \\
0.115 \\
-0.178 \\
-0.107 \\
-0.756 \\
0.828 \\
-0.823 \\
0.773\end{array}$ & $\begin{array}{r}0.020 \\
-0.868 \\
-0.847 \\
0.389 \\
0.503 \\
0.495 \\
-0.283 \\
0.146 \\
0.160 \\
-0.641 \\
0.070 \\
-0.121 \\
-0.058 \\
0.152 \\
0.223 \\
0.109 \\
0.186 \\
0.373 \\
0.092 \\
0.321 \\
-0.294 \\
-0.123 \\
-0.169 \\
0.085 \\
-0.018 \\
0.052 \\
-0.087 \\
2.055\end{array}$ & $\begin{array}{r}0.002 \\
0.020 \\
-0.138 \\
0.393 \\
0.325 \\
0.196 \\
0.375 \\
0.006 \\
0.203 \\
0.165 \\
0.065 \\
-0.260 \\
-0.102 \\
0.065 \\
0.091 \\
0.672 \\
0.213 \\
0.577 \\
0.029 \\
-0.668 \\
0.327 \\
0.417 \\
-0.681 \\
-0.059 \\
-0.047 \\
-0.047 \\
-0.241 \\
0.130\end{array}$ & $\begin{array}{r}0.900 \\
-0.117 \\
-0.124 \\
0.631 \\
0.561 \\
0.618 \\
0.231 \\
-0.017 \\
0.101 \\
0.003 \\
0.082 \\
0.068 \\
0.214 \\
0.104 \\
0.240 \\
0.167 \\
0.301 \\
0.174 \\
0.074 \\
-0.133 \\
-0.243 \\
0.157 \\
0.327 \\
-0.146 \\
-0.123 \\
0.242 \\
-0.031 \\
2.262\end{array}$ \\
\hline Variance extacted (\%) & 21.6 & 11.51 & 14.4 & 11.4 & 9.7 & 9.5 \\
\hline
\end{tabular}

Table 7. Rotat factor lowding matrix of finst PCA rewut. Primary loadings are in bold type. This was the trellth stage.

\begin{tabular}{|c|c|c|c|c|}
\hline \multirow[b]{2}{*}{ VARIABLE } & \multicolumn{4}{|c|}{ FACTOR } \\
\hline & 1 & 2 & 3 & 4 \\
\hline $\mathrm{pH}(\mathrm{H} 2 \mathrm{O}) \mathrm{A}$ & -0.164 & -0.837 & 0.083 & 0.176 \\
\hline pt (Ka) A & -0.272 & -0.862 & 0.078 & 0.123 \\
\hline KA & 0.225 & 0.688 & 0.529 & 0.042 \\
\hline CA & 0.296 & 0.753 & 0.446 & 0.036 \\
\hline $\operatorname{Mg} A$ & 0.102 & 0.727 & 0.577 & -0.047 \\
\hline$C A B$ & 0.906 & 0.168 & 0.201 & .0 .136 \\
\hline$M A B$ & 0.710 & 0.251 & 0.438 & 0.241 \\
\hline$K A B$ & 0.811 & 0.147 & 0.288 & 0.060 \\
\hline $\mathrm{PH}(H-\infty) A B$ & -0.776 & -0.160 & 0.076 & -0.386 \\
\hline $\mathrm{PH}$ (KC) AB & -0.749 & -0.030 & 0.377 & 0.264 \\
\hline $\mathrm{Ca} \mathrm{Bt}$ & 0.847 & 0.228 & 0.330 & -0.117 \\
\hline 咩 & 0.718 & 0.356 & 0.389 & 0.140 \\
\hline $\mathrm{K} \mathbf{B t}$ & 0.602 & 0.333 & 0.561 & 0.036 \\
\hline Thictenose Bt & -0.175 & 0.092 & 0.393 & -0.719 \\
\hline Color $A B$ & 0.167 & -0.293 & -0.077 & 0.763 \\
\hline Color Bt & 0.047 & 0.046 & 0.167 & 0.871 \\
\hline Extractable acidity $\mathrm{Bt}$ & 0.398 & 0.019 & -0.084 & -0.778 \\
\hline Cay $A$ & 0.092 & 0.031 & 0.849 & 0.005 \\
\hline Sat $A$ & -0.227 & -0.037 & -0.789 & 0.275 \\
\hline Coy 8 & 0.124 & 0.144 & 0.807 & 0.323 \\
\hline sat Bt & $=0.167$ & $=0.064$ & 20.815 & 2.111 \\
\hline Variane & & & & \\
\hline extracwd $(\%)$ & 25.307 & 17.009 & 22.473 & 14.472 \\
\hline
\end{tabular}


Table \&. Newne $\alpha$, and amounts of varianos extreated by, the factors of the thal Pitidpol Componont Anaryste solution.

\begin{tabular}{|c|c|c|}
\hline FACTOR MLABER & FACTOR NALE & VARLANCE EXTRACTED (\%) \\
\hline 1 & Subsurfeo chemibty & 25.3 \\
\hline 4 & Drsingege and thickn & 14.5 \\
\hline 3 & Soll texture & 22.5 \\
\hline 2 & A horkon & 17.0 \\
\hline
\end{tabular}

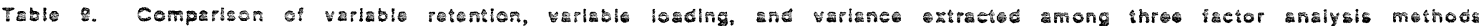
(SAS) and pincipal component (SYSTAT). The number represents the facter upon whieh the variable loaded. The dashed line indicates that the variable was not rotained by the ensiytleal procedure.

\begin{tabular}{|c|c|c|c|c|}
\hline & & & URE & \\
\hline Yaplenta & Examum & 10098 & Minimum & Prinelpal \\
\hline
\end{tabular}

AHerizen
Organic matter
PH $\left(\mathrm{H}_{2} \mathrm{O}\right)$
$\mathrm{PH}(\mathrm{KCl})$
$\mathrm{Ca}$
$\mathrm{Hg}$
$\mathrm{K}$
$\mathrm{Na}$
Thicknos
Color
Eztracteble scldity
Slit
Clay

\section{$\triangle B$ HORIZON}

$\mathrm{PH}\left(\mathrm{H}_{2} \mathrm{O}\right)$

PH (KCl)

$\mathrm{Ca}$

$M g$

$\mathrm{K}$

$K$

Thleknes

Color

Exiractable acldity

BI HORIZON

$\mathrm{pH}\left(\mathrm{H}_{2} \mathrm{O}\right)$

$\mathrm{PH}(\mathrm{KCl})$

$\mathrm{Ca}$

He

$\kappa$

$\mathrm{Ka}$

Thlekness

Color

Extractoble acldity

Sllt

Cisy

$\begin{array}{ll}2 & 2 \\ 2 & 2 \\ 2 & 2 \\ 2 & 2 \\ 2 & 2 \\ 2 & 2 \\ - & - \\ 2 & - \\ - & - \\ 3 & 2 \\ 2 & 2\end{array}$

2
2
2
2
2
-
-
-
2

$\begin{array}{ll}1 & 1 \\ 1 & 1 \\ 1 & 1 \\ 1 & 1 \\ 1 & 1 \\ - & 1 \\ 4 & - \\ - & 4\end{array}$

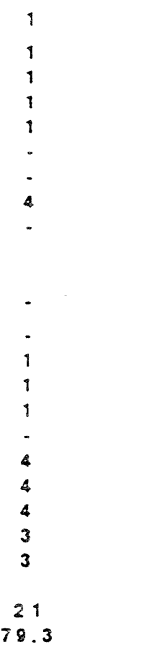

